\title{
Testing Inner-Mesowear III on goats (Capra aegagrus hircus) fed experimental diets
}

Stauffer, Julian B ; Clauss, Marcus ; Müller, Dennis W H ; Hatt, Jean-Michel ; Ackermans, Nicole L

\begin{abstract}
The wear patterns on ungulate's teeth help to understand dietary habits during an individual's lifetime. Mesowear is a series of techniques used to detect tooth wear patterns at low magnification. While in mesowear I, and its simplified version mesowear II, the outer profile of a herbivore's molar cusps is observed to assign a diet, mesowear III (or inner-mesowear) scores the wear facets on the inner enamel band of the tooth. This approach was developed to detect finer dietary signals for shorter periods than the two former mesowear methods. We tested this method on skulls of 26 goats (Capra aegagrus hircus) fed different diets for six months, for which mesowear I and II had already been scored. Our goal was to explore the effects of diets with varying abrasiveness on the dietary signal, comparing signals recorded with both techniques. We found no dif- ferences in mesowear III signals among diets, regardless of visible tendency of more abrasive diets leading to higher mesowear scores. We also found no difference in time resolution between mesowear III and I.
\end{abstract}

DOI: https://doi.org/10.5735/086.056.0108

Posted at the Zurich Open Repository and Archive, University of Zurich

ZORA URL: https://doi.org/10.5167/uzh-177547

Journal Article

Published Version

Originally published at:

Stauffer, Julian B; Clauss, Marcus; Müller, Dennis W H; Hatt, Jean-Michel; Ackermans, Nicole L (2019). Testing Inner-Mesowear III on goats (Capra aegagrus hircus) fed experimental diets. Annales Zoologici Fennici, 56(1-6):85-91.

DOI: https://doi.org/10.5735/086.056.0108 


\title{
Testing inner-mesowear III on goats (Capra aegagrus hircus) fed experimental diets
}

\author{
Julian B. Stauffer ${ }^{1}$, Marcus Clauss², Dennis W. H. Müller ${ }^{3}$, Jean-Michel Hatt ${ }^{2}$ \& \\ Nicole L. Ackermans ${ }^{2, *}$
}

\author{
1) University of Zurich, $\mathrm{CH}-8006$ Zurich, Switzerland \\ 2) Clinic for Zoo Animals, Exotic Pets and Wildlife, Vetsuisse Faculty, University of Zurich, $\mathrm{CH}-8057$ \\ Zurich, Switzerland ('corresponding author's e-mail: nicole.ackermans@uzh.ch) \\ 3) Zoologischer Garten Halle GmbH, D-06114 Halle (Saale), Germany
}

Received 10 May 2019, final version received 24 July 2019, accepted 24 July 2019

Stauffer, J. B., Clauss, M., Müller, D. W. H., Hatt, J.-M. \& Ackermans, N. L. 2019: Testing inner-mesowear III on goats (Capra aegagrus hircus) fed experimental diets. - Ann. Zool. Fennici 56: 85-91.

The wear patterns on ungulate's teeth help to understand dietary habits during an individual's lifetime. Mesowear is a series of techniques used to detect tooth wear patterns at low magnification. While in mesowear I, and its simplified version mesowear II, the outer profile of a herbivore's molar cusps is observed to assign a diet, mesowear III (or inner-mesowear) scores the wear facets on the inner enamel band of the tooth. This approach was developed to detect finer dietary signals for shorter periods than the two former mesowear methods. We tested this method on skulls of 26 goats (Capra aegagrus hircus) fed different diets for six months, for which mesowear I and II had already been scored. Our goal was to explore the effects of diets with varying abrasiveness on the dietary signal, comparing signals recorded with both techniques. We found no differences in mesowear III signals among diets, regardless of visible tendency of more abrasive diets leading to higher mesowear scores. We also found no difference in time resolution between mesowear III and I.

\section{Introduction}

Mesowear is a series of methods used to assess paleodiets of herbivorous ungulates by analysing different morphological aspects of the animal's molars. Mesowear signals are detectable by the naked eye or at low magnification, and can reflect a considerable fraction of an individual's diet during its lifespan (Fortelius \& Solounias 2000). Tooth wear patterns are divided into the wear modes of abrasion and attrition that are the result of food-on-tooth and tooth-on-tooth wear, respectively. By evaluating the relative severity of attrition as well as abrasion and scoring these wear modes accordingly, mesowear can be used to separate herbivorous ungulates into different diet groups, ranging from grazers to browsers (Fortelius \& Solounias 2000). While grazers typically show abrasion-dominated tooth wear, resulting in low, blunt cusps on the molar crowns, browsers cover the other end of the herbivorous dietary spectrum with attrition-dominated tooth wear, showing higher, sharper molar cusps. Though successfully applied in many instances to observational data of extant as well as extinct species (Franz-Odendaal \& Kaiser 2003, Clauss 
et al. 2007, Rivals et al. 2007, Schulz et al. 2007, Croft \& Weinstein 2008), mesowear has rarely been applied to animals fed experimental diets in controlled conditions (Solounias et al. 2014, Kropacheva et al. 2017, Ackermans et al. 2018), so understanding the extent of the dietary signal assessed by mesowear scoring is therefore still limited.

During the last 20 years, mesowear techniques were constantly developed and adapted to new tasks. Originally developed by Fortelius and Solounias (2000), the mesowear method consisted of two tooth characters: the cusp shape and the cusp relief of ungulate upper molars, scored for one apex per individual. This was further expanded to lower molars for equids (Kaiser \& Fortelius 2003) and artiodactyls (Franz-Odendaal \& Kaiser 2003). The original technique and its expanded version were termed "mesowear I" by Solounias et al. (2014). A new, four-point scoring approach was then introduced by Mihlbachler and Solounias (2006), and was named "mesowear type II" - this is a more simplified method of measuring mesowear I, and the two are considered equivalent in this paper. The mesowear method has since then been further extended, simplified or adapted for specific species (reviewed in Green \& Croft 2018). The "mesowear III" technique, also called "inner mesowear", was established by Solounias et al. (2014), and pertains to scoring the wear facets of the inner second enamel band (previous versions scoring the outer third enamel band, visible on the tooth's profile). This technique was established in order to detect a shorter-term signal with more precision, and was originally used in an experiment lasting for 40 days, a period considered likely too short to record a signal using mesowear I or II. Mesowear III was also used on its own to fossil camelid teeth (Bravo-Cuevas \& Jiménez-Hidalgo 2015), in combination with mesowear II on Miocene giraffids (Danowitz et al. 2016, Solounias \& Danowitz 2016) and extant artiodactyls alongside the experimental goats in Solounias et al. (2014), and in combination with mesowear I on fossil bison (DíazSibaja et al. 2018) and Pleistocene ungulates (Strani et al. 2018b, Strani et al. 2018c, Strani et al. 2018a). Although combining the methods provides robustness, the methods do not always produce identical results for each species at different time scales.

As we had already applied the expanded mesowear I technique to goats fed experimental diets of varying abrasiveness for six months (Ackermans et al. 2018), in this study we applied mesowear III to the same set of samples to compare the two techniques. As in the previous experiment, mesowear I had not yielded a significant difference among the feeding groups, we expected mesowear III to be able to differentiate among these groups. We therefore anticipated that abrasive-rich diets would result in higher mesowear III scores than less abrasive ones.

\section{Methods}

\section{Animals and their diet}

The animal experiments were performed with approval of the Swiss Cantonal Animal Care and Use Committee Zurich (animal experiment license no. 115/2009). The skulls analysed in the present study are housed in the mammal collection at the Center of Natural History, University of Hamburg (ID numbers in Table 1).

The animals were all domestic-goat (Capra aegagrus hircus) does $(n=28)$ from mixed breeds with unknown feeding history. They were the same individuals as those used in Ackermans et al. (2018), as were the diets and feeding regimes, the duration of the feeding experiment, and the skull preparation. In short, prior to the beginning of the experiment, all individuals were fed ad libitum lucerne (Medicago sativa) hay and lucerne pellets for two weeks. Subsequently, the goats were randomly divided into four groups of seven animals. For about six months, each group was fed one of the following four diets varying in abrasiveness: lucerne (L), no abrasives; grass (G), low in phytoliths; grass and rice husks (GR), high in phytoliths; grass, rice husks and sand (GRS), high in phytoliths and high abrasives. These diets were from the same batch as used in experiments with rabbits (Oryctolagus cuniculus) by Müller et al. (2014). The experimental diets were provided as pellets, $1500 \mathrm{~g}$ per animal per day, in addition to $100 \mathrm{~g}$ per animal per day of either lucerne hay for the lucerne group, or grass 
hay for the remaining three dietary groups. To make sure that the levels of energy and nutrients in the pelleted diets were comparable, they were formulated to be isocaloric and isonitrogenic (using an indigestible, non-silicacious filler and soybean meal) (cf. Müller et al. 2014). Water was available ad libitum.

\section{Mesowear III}

In the mesowear III method (Solounias et al. 2014), scores from 1 to 4 are assigned to the occlusal view of the inner enamel band of molar teeth. Score 1 reflects a typical browser wear pattern (sharp edge, flat surface), and score 4 a typical grazer pattern (round edge, uniform arched surface). For scoring, the enamel band is divided into three sections which are scored separately: (1) the mesial part, (2) the distal part and (3) the midpoint of these two areas named $\mathrm{j}$ for junction. As suggested by Solounias et al. (2014) and Danowitz et al. (2016), we also calculated averages of the mesial and distal scores to obtain a mean score (cf. Tables 1 and 2). In this study, primarily the paracone of the second right-side

Table 1. Mesowear III scores on molars of domesticated goats (Capra aegagrus hircus, $n=26$ ), fed experimental diets for six months.

\begin{tabular}{|c|c|c|c|c|c|c|c|c|c|}
\hline \multirow{2}{*}{$\begin{array}{l}\text { Animal } \\
\text { ID }^{\mathbf{a}}\end{array}$} & \multirow[t]{2}{*}{ ZMH ID } & \multirow[t]{2}{*}{ Tooth $^{c}$} & \multirow[t]{2}{*}{ Diet $^{d}$} & \multirow[t]{2}{*}{ Side } & \multicolumn{3}{|c|}{ Mesowear III score } & \multicolumn{2}{|c|}{ Score } \\
\hline & & & & & distale $^{\mathbf{e}}$ & mesialf $^{f}$ & $\mathrm{jg}^{\mathrm{g}}$ & average & ranked \\
\hline 1 & 10879 & M3 & GRS & left & 2 & 2 & 3 & 2 & 3 \\
\hline 2 & 10880 & M2 & GRS & right & 3 & 4 & 4 & 3.5 & 6 \\
\hline $3^{\text {h }}$ & 10881 & M2 & $\mathrm{L}$ & right & & & & & \\
\hline $4^{\mathrm{h}}$ & 10882 & M2 & GR & right & & & & & \\
\hline 5 & 10883 & M3 & $\mathrm{G}$ & right & 4 & 4 & 3 & 4 & 7 \\
\hline 6 & 10884 & M2 & GRS & right & 3 & 3 & 2 & 3 & 5 \\
\hline 7 & 10885 & M2 & GR & right & 3 & 3 & 2 & 3 & 5 \\
\hline 8 & 10886 & M2 & GR & right & 2 & 3 & 4 & 2.5 & 4 \\
\hline 9 & 10887 & M2 & $\mathrm{G}$ & left & 3 & 3 & 4 & 3 & 5 \\
\hline 10 & 10888 & M2 & $\mathrm{L}$ & right & 3 & 4 & 4 & 3.5 & 6 \\
\hline 11 & 10889 & M2 & L & left & 4 & 3 & 3 & 3.5 & 6 \\
\hline 12 & 10890 & M2 & GR & right & 2 & 3 & 2 & 2.5 & 4 \\
\hline 13 & 10891 & M2 & $\mathrm{L}$ & right & 2 & 3 & 2 & 2.5 & 4 \\
\hline 14 & 10892 & M2 & $\mathrm{G}$ & right & 3 & 3 & 3 & 3 & 5 \\
\hline 15 & 10893 & M2 & $\mathrm{L}$ & right & 2 & 3 & 2 & 2.5 & 4 \\
\hline 16 & 10894 & M2 & GR & right & 3 & 2 & 3 & 2.5 & 4 \\
\hline 17 & 10895 & M2 & $\mathrm{G}$ & right & 2 & 2 & 2 & 2 & 3 \\
\hline 18 & 10896 & M2 & GRS & right & 4 & 3 & 3 & 3.5 & 6 \\
\hline 19 & 10897 & M2 & GRS & right & 3 & 4 & 3 & 3.5 & 6 \\
\hline 20 & 10898 & M2 & GRS & right & 3 & 4 & 3 & 3.5 & 6 \\
\hline 21 & 10899 & M2 & $\mathrm{G}$ & right & 2 & 2 & 4 & 2 & 3 \\
\hline 22 & 10900 & M2 & GR & right & 3 & 3 & 3 & 3 & 5 \\
\hline 23 & 10901 & M2 & $\mathrm{L}$ & left & 1 & 2 & 2 & 1.5 & 2 \\
\hline 24 & 10902 & M2 & L & right & 2 & 1 & 1 & 1.5 & 2 \\
\hline 25 & 10903 & M2 & GR & right & 4 & 3 & 3 & 3.5 & 6 \\
\hline 26 & 10904 & M2 & GRS & right & 3 & 4 & 2 & 3.5 & 6 \\
\hline 27 & 10905 & M2 & $\mathrm{G}$ & right & 2 & 2 & 2 & 2 & 3 \\
\hline 28 & 10906 & M2 & $\mathrm{G}$ & right & 1 & 1 & 1 & 1 & 1 \\
\hline
\end{tabular}

a same as in Ackermans et al. (2018).

${ }^{b}$ ID numbers assigned by the Zoological Museum of Hamburg.

c M2 = maxillary second molar, M3 = maxillary third molar.

${ }^{\mathrm{d}} \mathrm{L}=$ lucerne, $\mathrm{G}$ = grass, $\mathrm{GR}=$ grass and rice husks, GRS = grass, rice husks and sand.

e mesowear III score assigned to the distal facet of the tooth's third enamel band.

f mesowear III score assigned to the mesial facet of the tooth's third enamel band.

g mesowear III score assigned to the midpoint of the tooth's third enamel band.

${ }^{\mathrm{h}}$ teeth too worn to be scored for mesowear III. 
mandibular molar was scored. If this tooth was too worn and/or damaged, the same location on the left-side mandibular molar was scored. If this tooth was also worn and/or damaged, the third molar was used for scoring. In all, we scored 22 maxillary right-side molars, of which one was the third molar and the rest second molars; and 4 maxillary left-side molars, of which one was the third molar and three were second molars. Two goat skulls had teeth too worn to be scored for mesowear III. The sample size was thus $n=26$.

Mesowear I scores of the same teeth were taken from Ackermans et al. (2018). In comparisons between mesowear I and III, animals that were not scored in either of the techniques were excluded, resulting in the sample size of $n=25$.

\section{Statistical analysis}

Because the mesowear III scores were not normally distributed, the data were analysed using non-parametric tests. The Kruskal-Wallis test was used to find out whether mesowear III scores differed among the diet groups, and Spearman's rank-order correlation analysis to study the relationships between III scores and between mesowear I and III scores. All analyses were performed in SPSS 22.0 (IBM, Armonk,
NY). Differences were considered significant and correlations existing at $p<0.05$. Although the data were non-normally distributed, standard deviation and means were plotted to better visualise possible differences (cf. Fig. 1).

\section{Results}

We found no statistical differences among diet groups when scoring tooth wear with mesowear III (Kruskal-Wallis test: $p=0.171$ for the mesial mesowear III score, $p=0.389$ for the distal mesowear III score, $p=0.212$ for the mean of the mesial and distal mesowear III score, and $p=0.700$ for the junction mesowear III score; Fig. 1). GRS, GR and $G$ diets tended to produce higher mean mesowear scores than the L diet for mesial, junction and averaged characters, while GRS and GR produced higher mean mesowear scores than the $\mathrm{L}$ and $\mathrm{G}$ diets for the distal character. GRS was the diet that resulted in the highest mean mesowear III score for all four mesowear III characters, and the diet with the lowest mean mesowear III score was either G or L. All measured mean mesowear III scores were greater than 2, most being between 2 and 3 (cf. Table 1). Although the four mesowear III scores were correlated ( $R$ between 0.43 and 0.90

Table 2. The scoring of mesial part, distal part and midpoint (j) of the tooth's third enamel band, and the score descriptions of mesowear III (following Danowitz et al. 2016) used to assess mesowear signals.

\begin{tabular}{|c|c|c|}
\hline Location & Score & Description \\
\hline mesial/distal & 1 & $\begin{array}{l}\text { The occlusal surface of the enamel band is flat and planar and there are no gouges } \\
\text { or indentations on the surface of the enamel. }\end{array}$ \\
\hline mesial/distal & 2 & $\begin{array}{l}\text { The surface of the enamel band is nearly flat and contains several gouges that } \\
\text { traverse the surface from either edge. The labial and lingual edges of the enamel } \\
\text { band are somewhat rounded. Instead of a single surface as in score } 1 \text {, several facets } \\
\text { are discernible. }\end{array}$ \\
\hline mesial/distal & 3 & $\begin{array}{l}\text { The enamel surface is similar to score } 2 \text {, but is more rounded with less defined edges } \\
\text { and more gouges. }\end{array}$ \\
\hline mesial/distal & 4 & $\begin{array}{l}\text { The enamel surface is rounded. The surface is smooth without gouges, and there are } \\
\text { no well-defined edges. }\end{array}$ \\
\hline midpoint & 1 & The mesial and distal surfaces join at a sharp, well-defined junction. \\
\hline midpoint & 2 & $\begin{array}{l}\text { The midpoint between the mesial and distal surfaces is somewhat sharp, and often } \\
\text { contains a gouge. }\end{array}$ \\
\hline midpoint & 3 & $\begin{array}{l}\text { The midpoint on the enamel band is rounded, but the mesial and distal sides appear } \\
\text { as distinct, separate surfaces. }\end{array}$ \\
\hline midpoint & 4 & $\begin{array}{l}\text { The j point lacks a discrete apex, and the mesial and distal sides of the enamel band } \\
\text { form one continuous surface. }\end{array}$ \\
\hline
\end{tabular}


Fig. 1. Mean ( \pm SD) mesowear III scores on molars of domesticated goats (Capra aegagrus hircus, $n=26$ ), fed four experimental diets for six months. The $x$-axis represents the three separately scored enamel characters (distal, mesial, junction) and the average of two of them $[($ mesial + distal)/2].

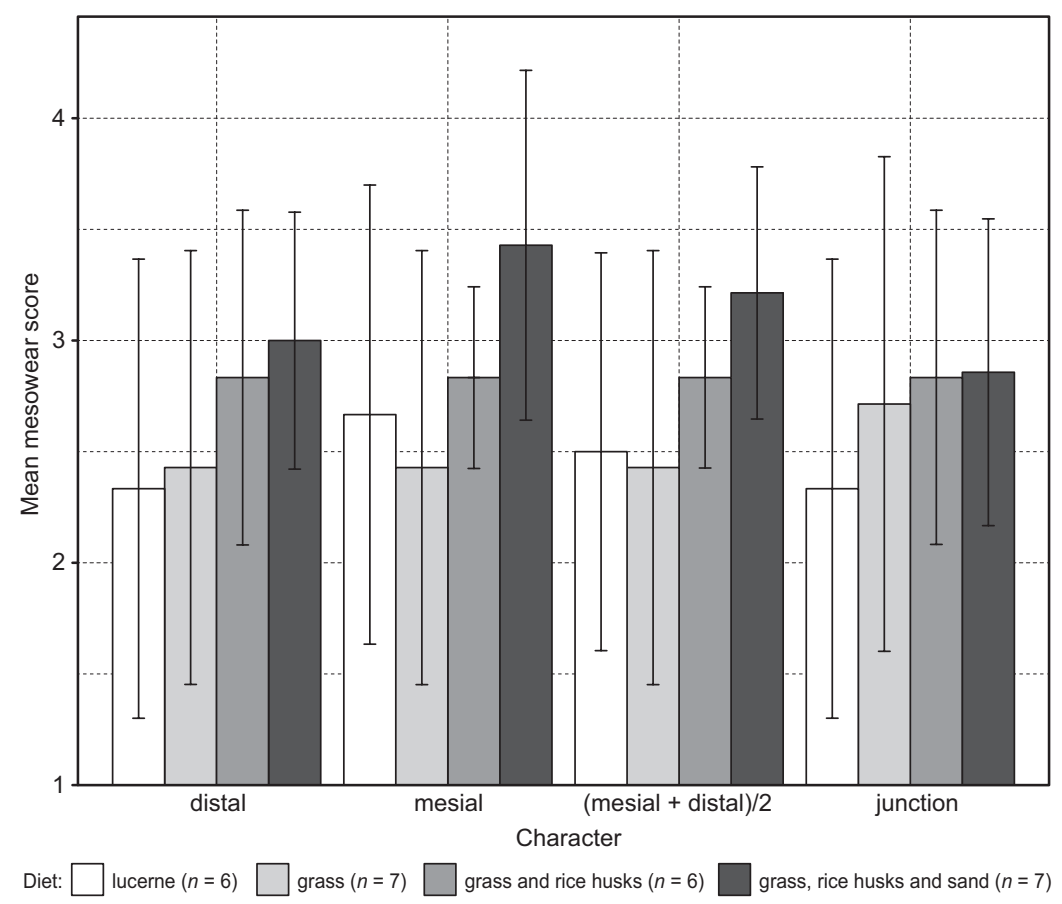

and $p$ between 0.031 and $<0.001$ ), none of the mesowear scores were correlated with the corresponding mesowear I cusp-score on the same tooth $(R=0.10-0.19, p=0.377-0.627)$.

\section{Discussion}

Diets differing in abrasiveness did not result in differences in maxillary M2 mesowear III scores in goats. Mesowear III scores seemed to increase with the diet abrasiveness (cf. Fig. 1), but this was not supported by the statistical analysis of the data. Similar results were found by Ackermans et al. (2018) for mesowear I.

In their original mesowear III study, Solounias et al. (2014) fed two groups of four goats browsing and grazing diets. On days 10, 20, 30 and 40 one goat from each group was sacrificed and their skulls and jaws were was skeletonised. They found that in the goats that shifted from natural food to browsing, the teeth became incrementally flatter after 30-40 days of browsing, while in the goats that shifted from natural food to grazing, the teeth had become incrementally rounder during the first 30 days of grazing, and did not change anymore during the last 10 days.
However, as Solounias et al. (2014) recognized themselves, their experimental setting had several weaknesses: all the goats had a browsing diet before the experiment, and the sample size was small (only one animal per sampling, hence no statistical comparisons were possible). In addition, the original wear state of these animals was based on mesowear III scored on other individuals feeding in the same location. Therefore individual differences in tooth wear among experimental goats at the start of the experiment could not be taken into account in the comparisons. As such, by applying mesowear III scoring in a longer-term experiment with a larger sample size, we hoped to ascertain the applicability of this technique. The lack of significant difference in mesowear scores among the goats fed the different diets in the present study indicates that six months may not be long enough for a stable mesowear I or III signal to develop.

Although the results obtained by Solounias et al. (2014) were considered preliminary, several subsequent studies used this technique. For example, Danowitz et al. (2016) showed that mesowears II and III are correlated when predicting browser or grazer profiles. The correlations between the two mesowear techniques, however, 
were weaker than those between mesowear III scores. As similar results were obtained in other studies as well (Strani et al. 2018b, Strani et al. 2018a), combined usage of mesowear II and III techniques has been recommended. BravoCuevas and Jiménez-Hidalgo (2015), however, used mesowear III alone to determine a browser or grazer diet. Even if mesowear III scores could distinguish between the two diet types, and could be considered a short-term dietary signal in this case, it should not be used as a stand-alone method to define species-specific, long-term, diets. It would thus be a good practice to systematically record mesowear I or II in conjunction with mesowear III.

The mesowear method is based on more or less subjective observations, and the descriptions of scoring can be interpreted differently depending on the observer, which is why a single observer is often used to reduce inter-observer errors. Another factor that could have affected the scoring in the present study were large age differences among individuals. Age can affect mesowear scores because an old, flat, and round tooth is scored as blunter, due to more abrasion, than a younger, sharper tooth. Additionally, differences in goat breeds and unknown previous diets might have also increased variations in the data set. On the other hand, obtaining a large number of animals with equal wear could be rather challenging. It might also be interesting to study whether goats might be less sensitive to mesowear changes than for example sheep, or whether ruminants as a group are less sensitive than non-ruminants, because ruminants can wash off external abrasives from their diet before rumination (Hatt et al. 2019), most likely reducing dental wear. Nevertheless, our finding that after 6 months of controlled feeding no produce differences among the diet groups, indicates that similarly to mesowear I, mesowear III should probably not be considered a short-term dietary signal by default until the signal length can be confirmed in additional experiments.

According to the results of this study, mesowear III could be used in combination with mesowear I or II by adding dietary signal information to a data set, but its relationship to mesowear I or II, as well as its responsiveness to the diet cannot so far be confirmed with certainty.
All in all, mesowear is the most cost-effective method to quickly determine the general diet of a large number of specimens. The time this technique requires to respond to different diets, however, remains to be experimentally determined.

\section{Conclusions}

Based on the results of our study we can conclude that, at least when small ruminants and short time intervals are concerned, mesowear III is not a finer tooth-wear measurement method than mesowear I or II. More caution is thus needed when it comes to applying mesowear, especially mesowear III, as the amount of time necessary for the dietary signal to develop, and the strength of the signal are not yet fully quantified.

\section{Acknowledgements}

This study was part of project 31003A_163300/1 funded by the Swiss National Science Foundation and was part of the AgroVet cooperation between Strickhof Eschikon and the Vetsuisse Faculty of the University of Zurich. We thank Anja Tschudin and Dietmar Ranz for their help in pelleted diet formulation, and Hanspeter Renfer, Lucy Taylor, Daryl Codron, Sonja Müller, Irene, Samuel, Emilia and Daniel Clauss for their assistance in animal husbandry, and Prof. Dr. Marcelo Sánchez-Villagra for access to research facilities at the Palaentological Institute and Museum of the University of Zürich. We also thank the two reviewers and the editor-in chief for their detailed and constructive comments, which greatly improved this manuscript.

\section{References}

Ackermans, N. L., Winkler, D. E., Schulz-Kornas, E., Kaiser, T. M., Müller, D. W. H., Kircher, P. R., Hummel, J., Clauss, M. \& Hatt, J.-M. 2018: Controlled feeding experiments with diets of different abrasiveness reveal slow development of mesowear signal in goats (Capra aegagrus hircus). - Journal of Experimental Biology 221: jeb186411, https://doi.org/10.1242/jeb.186411.

Bravo-Cuevas, V. M. \& Jiménez-Hidalgo, E. 2015: First reported occurrence of Palaeolama mirifica (Camelidae, Lamini) from the Late Pleistocene (Rancholabrean) of Puebla, central Mexico. — Boletín de la Sociedad Geológica Mexicana 67: 13-20.

Clauss, M., Franz-Odendaal, T. A., Brasch, J., Castell, J. C. \& Kaiser, T. 2007: Tooth wear in captive giraffes (Giraffa 
camelopardalis): mesowear analysis classifies free-ranging specimens as browsers but captive ones as grazers. Journal of Zoo and Wildlife Medicine 38: 433-445.

Croft, D. A. \& Weinstein, D. 2008: The first application of the mesowear method to endemic South American ungulates (Notoungulata). - Palaeogeography, Palaeoclimatology, Palaeoecology 269: 103-114.

Danowitz, M., Hou, S., Mihlbachler, M., Hastings, V. \& Solounias, N. 2016: A combined-mesowear analysis of late Miocene giraffids from North Chinese and Greek localities of the Pikermian Biome. - Palaeogeography, Palaeoclimatology, Palaeoecology 449: 194-204.

Díaz-Sibaja, R., Jiménez-Hidalgo, E., Ponce-Saavedra, J. \& García-Zepeda, M. L. 2018: A combined mesowear analysis of Mexican Bison antiquus shows a generalist diet with geographical variation. - Journal of Paleontology 92: 1130-1139.

Fortelius, M. \& Solounias, N. 2000: Functional characterization of ungulate molars using the abrasion-attrition wear gradient: a new method for reconstructing paleodiets. American Museum Novitates 3301: 1-36.

Franz-Odendaal, T. A. \& Kaiser, T. M. 2003: Differential mesowear in the maxillary and mandibular cheek dentition of some ruminants (Artiodactyla). - Annales Zoologici Fennici 40: 395-410.

Green, J. L. \& Croft, D. A. 2018: Using dental mesowear and microwear for dietary inference: a review of current techniques and applications. - In: Croft, D. A., Su, D. F. \& Simpson, S. W. (eds.), Methods in paleoecology: reconstructing Cenozoic terrestrial environments and ecological communities: 53-73. Springer International Publishing, Cham.

Hatt, J.-M., Codron, D., Müller, D. W. H., Ackermans, N. L., Martin, L. F., Kircher, P. M., Hummel, J. \& Clauss, M. 2019: The rumen washes off abrasives before heavyduty chewing in ruminants. - Mammalian Biology 97: 104-111.

Kaiser, T. M. \& Fortelius, M. 2003: Differential mesowear in occluding upper and lower molars: opening mesowear analysis for lower molars and premolars in hypsodont horses. - Journal of Morphology 258: 67-83.

Kropacheva, Y. E., Sibiryakov, P. A., Smirnov, N. G. \& Zykov, S. V. 2017: Variants of tooth mesowear in Microtus voles as indicators of food hardness and abrasiveness. - Russian Journal of Ecology 48: 73-80.
Mihlbachler, M. C. \& Solounias, N. 2006: Coevolution of tooth crown height and diet in oreodonts (Merycoidodontidae, Artiodactyla) examined with phylogenetically independent contrasts. - Journal of Mammalian Evolution 13: 11-36.

Müller, J., Clauss, M., Codron, D., Schulz, E., Hummel, J., Fortelius, M., Kircher, P. \& Hatt, J.-M. 2014. Growth and wear of incisor and cheek teeth in domestic rabbits (Oryctolagus cuniculus) fed diets of different abrasiveness. - JEZ-A 321: 283-298. [https://doi.org/10.1002/ jez.1864].

Rivals, F., Mihlbachler, M. C. \& Solounias, N. 2007: Effect of ontogenetic-age distribution in fossil and modern samples on the interpretation of ungulate paleodiets using the mesowear method. - Journal of Vertebrate Paleontology 27: 763-767.

Schulz, E., Fahlke, J. M., Merceron, G. \& Kaiser, T. M. 2007: Feeding ecology of the Chalicotheriidae (Mammalia, Perissodactyla, Ancylopoda). Results from dental micro-and mesowear analyses. - Verhandlungen des Naturwissenschaftlichen Vereins zu Hamburg 43: 5-31.

Solounias, N. \& Danowitz, M. 2016: The Giraffidae of Maragheh and the identification of a new species of Honanotherium. - Palaeobiodiversity and Palaeoenvironments 96: 489-506.

Solounias, N., Tariq, M., Hou, S., Danowitz, M. \& Harrison, M. 2014: A new method of tooth mesowear and a test of it on domestic goats. - Annales Zoologici Fennici 51: $111-118$.

Strani, F., DeMiguel, D., Sardella, R. \& Bellucci, L. 2018a: Resource and niche differentiation mechanisms by sympatric Early Pleistocene ungulates: the case study of Coste San Giacomo. - Quaternary International 481: 157-163.

Strani, F., DeMiguel, D., Bellucci, L. \& Sardella, R. 2018b: Dietary response of early Pleistocene ungulate communities to the climate oscillations of the Gelasian/ Calabrian transition in Central Italy. - Palaeogeography, Palaeoclimatology, Palaeoecology 499: 102-111.

Strani, F., DeMiguel, D., Bona, F., Sardella, R., Biddittu, I., Bruni, L., De Castro, A., Guadagnoli, F. \& Bellucci, L. 2018c: Ungulate dietary adaptations and palaeoecology of the Middle Pleistocene site of Fontana Ranuccio (Anagni, Central Italy). - Palaeogeography, Palaeoclimatology, Palaeoecology 496: 238-247. 